\title{
Visibilidade lésbica: existência como resistência
}

\author{
Kamylla Cavalcante Taques dos Reis $^{1}$ \\ Moisés Lopes ${ }^{2}$ \\ Universidade Federal de Mato Grosso
}

Resumo: Este artigo tem por objetivo desenvolver uma análise sobre a construção da saúde e políticas públicas para mulheres lésbicas, explorando a vulnerabilidade em saúde por compreender sua situação de invisibilidade social que resulta na impercepção de suas demandas junto aos serviços de saúde. Para tanto, utilizamos teorias de gênero e sexualidade como subsídio teórico às proposições realizadas, bem como dados de campo provenientes de observação participante em um Serviço Especializado em IST/HIV/Aids de Cuiabá. Retomar a discussão sobre visibilidade e existência lésbica, está além da área acadêmica, envolvendo os movimentos sociais LGBTI+ e o feminismo em si, aspirando contemplar a gama de diversidade que as mulheres apresentam, levando em consideração seu contexto histórico-social e sua agência enquanto sujeito de direitos, refletindo sobre a temática e questionando o efeito das produções acadêmicas nas mudanças sociais.

Palavras-chave: feminismo; lesbianidade; direitos sexuais; saúde; interseccionalidade. 


\title{
Lesbian visibility: existence as resistance
}

\begin{abstract}
This article aims to develop an analysis on the construction of health and public policies for lesbian women, exploring the vulnerability in health by understanding their situation of social invisibility that results in the imperceptibility of their demands with health services. For that, we used theories of gender and sexuality as a theoretical subsidy to the proposals made, as well as field data from participant observation in a Specialized Service on STI/HIV/AIDS in Cuiabá. Resuming the discussion on lesbian visibility and existence, is beyond the academic area, involving LGBTI + social movements and feminism itself, aiming to contemplate the range of diversity that women present, taking into account their historical-social context and their agency as a subject rights, reflecting on the theme and questioning the effect of academic productions on social changes.
\end{abstract}

Keywords: feminism; lesbianity; sexual rights; health; intersectionality.

\section{Visibilidad lesbiana: existencia como resistência}

Resumen: Este artículo tiene como objetivo desarrollar un análisis sobre la construcción de políticas públicas y de salud para mujeres lesbianas, explorando la vulnerabilidad en salud al comprender su situación de invisibilidad social que resulta en la imperceptibilidad de sus demandas con los servicios de salud. Para ello, utilizamos teorías de género y sexualidad como subsidio teórico a las propuestas realizadas, así como datos de campo de observación participante en un Servicio Especializado en ITS / VIH / SIDA en Cuiabá. Reanudar la discusión sobre la visibilidad y existencia lesbiana, va más allá del ámbito académico, involucrando a los movimientos sociales LGBTI + y al propio feminismo, con el objetivo de contemplar el abanico de diversidad que presentan las mujeres, teniendo en cuenta su contexto históricosocial y su agencia como sujeto. derechos, reflexionando sobre el tema y cuestionando el efecto de las producciones académicas en los cambios sociales.

Palabras-clave: feminismo; lesbianidad; derechos sexuales; salud; interseccionalidad. 


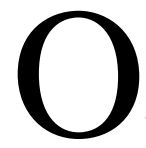
objetivo deste texto é desenvolver uma análise sobre a construção da saúde, e políticas públicas para mulheres lésbicas. Trata-se de um ensaio teórico bibliográfico, com dados complementares obtidos em pesquisa de campo, que tem como fim levantar hipóteses sobre as maneiras nas quais a (in)visibilidade lésbica e a não-inteligibilidade em saúde vem ao longo de décadas promovendo, direta ou indiretamente, a vulnerabilização social e em saúde destas mulheres. Assim, buscamos mostrar como esta invisibilidade das experiências lésbicas tem um caráter produtivo, isto é, espraiam-se e produzem efeitos na vida prática destas mulheres, uma vez que mesmo quando citadas em políticas públicas de saúde tem suas inserções pontuais pautadas em uma visão que segue atrelando a saúde da mulher e sua sexualidade a elementos reprodutivos, de violência e envoltos em uma matriz heterossexual. Tal como apontam Carvalho, Calderaro e Souza (2013: 123)

\footnotetext{
A saúde sexual lésbica parece trilhar os mesmos caminhos espinhosos, colocando a lésbica como vítima seja da violência ou de doenças (argumentos biomédicos) não cabendo até agora espaço para se falar de práticas sexuais, de prazer, de desejo.
}

Para percorrer este caminho, trilharemos uma análise que enfocará, a partir de uma perspectiva feminista e antropológica, o campo das políticas e da produção científica, problematizando como os discursos e a produção da saúde para mulheres lésbicas vem sendo efetivado. Partiremos também de nossas experiências de trabalho, pesquisa e de observação, tanto no Conselho Municipal de Atenção a Diversidade Sexual de Cuiabá onde um de nós - Moisés Lopes - representa a UFMT, bem como da experiência deste pesquisador desenvolvendo investigação sobre o Movimento LGBTI+ de Mato Grosso desde 2011. Outrossim, tomamos como central a experiência da outra coautora - Kamylla Reis -, que vem trabalhando com a temática da saúde LGBTI+ desde 2017, a partir de sua experiência como enfermeira assistencial em serviços especializados em IST/HIV/Aids e hepatites virais em Cuiabá.

Neste sentido, antes de iniciarmos a discussão é de fundamental importância ressaltar que nossa compreensão de saúde não se limita a ausência de doenças, mas adquire um sentido social e coletivo que ultrapassa uma visão biologicista. Esta visão mais ampla está inclusive amparada no artigo $3^{\circ}$ da lei 8.080/1990 (Lei Orgânica da Saúde), que ressalta as relações entre determinantes sociais como a alimentação, a moradia, o saneamento básico, bem como condições de trabalho, renda e educação como elementos que impactam nas condições de saúde dos sujeitos e dos grupos. Em suas palavras,

\footnotetext{
Os níveis de saúde expressam a organização social e econômica do País, tendo a saúde como determinantes e condicionantes, entre outros, a alimentação, a moradia, o saneamento básico, o meio ambiente, o trabalho, a renda, a educação, a atividade física, o transporte, o lazer e o acesso aos bens e serviços essenciais. (BRASIL, 1990)
}

No entanto, é importante ressaltar, tal como aponta Tatiana Lionço (2008: 18) a partir de uma análise das políticas públicas de saúde e sua implementação, a necessidade de formulação de políticas públicas especializadas para LGBTI+ com o intuito de se obter a universalidade do acesso à saúde, haja vista as necessidades específicas e os agravos de saúde oriundos das LGBTfobias para que sejam ressaltadas "estratégias de acolhimento e atenção específicas, de acordo com as particularidades dos sujeitos que buscam os serviços de saúde". É interessante destacar que o SUS avançou com a publicação da Carta dos Direitos dos Usuários 
da Saúde pelo Ministério da Saúde em 2009 que indica no parágrafo único do artigo $4^{\circ}$ :

É direito da pessoa, na rede de serviços de saúde, ter atendimento humanizado, aco-
lhedor, livre de qualquer discriminação, restrição ou negação em virtude de idade, raça,
cor, etnia, religião, orientação sexual, identidade de gênero, condições econômicas ou
sociais, estado de saúde, de anomalia, patologia ou deficiência [...]. (BRASIL, 2012: 13)

Apesar deste avanço, como aponta o movimento de lésbicas e mulheres bissexuais no documento "Atenção à Saúde Integral de Mulheres Lésbicas e Bissexuais" resultante de uma oficina realizada em 2014 em Brasília,

O acolhimento a lésbicas não tem funcionado adequadamente. Teoricamente o SUS é preparado para atender a essa população, como está previsto na Carta dos Usuários do SUS. A base para que as coisas aconteçam estão dadas em diversos documentos, mas mulheres não dizem que são lésbicas e profissionais não perguntam. Não há materialização do que está na teoria. (BRASIL, 2014: 26)

Concluindo, gostaríamos de destacar que este artigo está dividido em três partes e uma consideração final. Na primeira parte, intitulada "Gênero, Saúde e Lesbianidade" debatemos a maneira como as questões que envolvem a lesbianidade e o gênero afetam de modo direto e indireto no acesso aos serviços de saúde; na parte seguinte, "Invisibilidade lésbica nas Políticas Públicas de Saúde" discutimos como a não-inteligibilidade de lésbicas nos serviços de saúde e nas Políticas Públicas de Saúde afetam o acesso destas mulheres ao atendimento integral; finalizando, no tópico nomeado como "Resistência ao apagamento social da mulher lésbica" destacamos a invisibilização da mulher lésbica e a possibilidade de utilizar as categorias de articulação para compreensão mais profunda deste apagamento.

\section{Gênero, saúde e lesbianidade}

A saúde de mulheres lésbicas é apontada na literatura para as seguintes questões de saúde: câncer de mama, câncer do colo do útero (ocasionado principalmente por HPV), saúde mental afetada por diversas formas de violência, consumo abusivo de álcool e outras drogas, ansiedade causada pelo medo e expectativa de rejeição relacionados à lesbofobia, e por fim as Infecções Sexualmente Transmissiveis (IST) (CARVALHO et al., 2013).

A desigualdade de gênero é condicionante de risco às mulheres por produzir uma relação assimétrica na sociedade, implicando em relações de poder desiguais em que o que se configura como feminino, exerce papel de subalternidade na organização social (FERREIRA et al., 2017; SAMPAIO et al., 2011). É precisamente essa relação de poder na qual a mulher está frequentemente em lugar de subserviência que a coloca em vulnerabilidade social, e consequentemente vulnerabilidade em saúde.

Ao se tratar de gênero é importante destacar dois pontos importantes: a atribuição de espaços sociais diferentes para homens e mulheres e a situação de opressão que as mulheres se encontram (PISCITELLI, 2009). Para efeito de apreender o significado de gênero e como a sua (in)compreensão afeta a situação de saúde das mulheres, destaca-se as teorias feministas como precursoras nesses estudos.

É notável nos estudos feministas, especialmente em Scott (1995), que gênero pode ser definido como um produto das relações sociais que é assimilado, representado e institucionalizado, repassado de uma geração para outra, baseado nas 
diferenças anatômicas percebidas entre os sexos, que configura o primeiro campo no qual as relações de poder se articulam (GOMES et al., 2018; FERREIRA et al., 2017).

Ainda de acordo com Scott (1995), o termo gênero funciona como uma categoria social imposta a um corpo sexuado, a partir dele é possível indicar a existência de uma construção social de ideias sobrepostas aos papéis socialmente adequados aos homens e mulheres, uma forma de refletir sobre as origens sociais das suas identidades subjetivas.

A opressão sobre as mulheres está vinculada à atribuição de qualidades e traços de temperamento a homens e mulheres, que delimitam seu espaço de atuação, frequentemente considerados inatos, ou seja, "naturais", relacionados a características anatômicas e essencialmente reprodutivas, com o cenário da mulher associado à capacidade de gerar filhos e criá-los, dentro de um espaço doméstico (ORTNER, 1979; PISCITELLI, 2009).

Uma das fragilidades nos cuidados em saúde sexual de mulheres que fazem sexo com mulheres, grupo em que as lésbicas estão inseridas, como descritas por Barbosa e Facchini (2009), é a menor frequência de realização de exames ginecológicos, tanto pela menor solicitação de exames por parte dos profissionais de saúde, como pela menor procura da lésbica por esse cuidado quando necessário ou apenas quando ocorre agravamento da situação de saúde.

As autoras também trazem a associação entre atributos corporais autorreferidos como "masculina" ou "mais masculinizada" com a menor frequência de busca por cuidados ginecológicos (BARBOSA e FACCHINI, 2009). Dado que demonstra um dos aspectos que dificultam o acesso dessas mulheres a serviços de saúde, pela relação entre a forma como o gênero é percebido na sociedade e no sistema de saúde, pautado em uma matriz heterossexual e reforçada pelo modelo de saúde biomédico, que atribui às mulheres a performance de uma feminilidade idealizada, que ao não ser correspondida, fisicamente ou em sua prática afetiva/sexual, ocasiona o estranhamento social expresso em atitudes (vexatórias, depreciativas, discriminatórias, negligentes etc) que causam desconforto às usuárias.

Veja abaixo a descrição de um trecho retirado do diário de campo de um momento observado em um serviço especializado em IST/HIV/Aids de Cuiabá:

Uma mulher, aproximadamente 22 anos, autodenominada lésbica, procurou a unidade para realização de teste rápido. Entrei em contato com a usuária ao entrar no consultório durante atendimento para pegar um material, porém, notando a usuária, que parecia ser menor de idade, decidi acompanhar a consulta com a enfermeira. No momento inicial a enfermeira perguntava a ela o motivo de buscar o atendimento, ela relatou estar namorando uma outra mulher que mora no sul do país e em alguns dias iria encontrá-la pela primeira vez. No entanto, há um ano, ela havia tido relações sexuais sem preservativo com uma mulher bissexual, e por isso estava preocupada em ter contraído alguma IST, por isso ela desejava realizar o teste rápido para ter certeza que estava tudo bem antes de se relacionar com a atual namorada, com a qual ela não tinha preocupações por ser lésbica também. No desenrolar do atendimento a enfermeira reforçava que não havia necessidade de realizar o teste rápido, dizia não haver risco de infecção ao transar com outra mulher, mas que ela faria para que a usuária ficasse mais tranquila. Os resultados foram não reagentes e a enfermeira estava prestes a liberar a usuária, quando intervi no atendimento, que até o momento havia acompanhado em silêncio. Comentei que apesar dos resultados não reagentes era bom que ela fizesse o teste rápido pelo menos duas vezes ao ano, $e$ que para além das infecções detectadas no teste rápido existem outras IST que são identificadas por exame clínico, como HPV, gonorréia e clamídia, nesse momento questionei quando havia sido o último exame ginecológico que ela havia realizado, momento em que ela afirmou nunca ter consultado com uma ginecologista. Nesse momento, a enfermeira mencionou que ela poderia realizar o exame ginecológico com a ginecologista do $S A E$, pois de acordo com ela os profissionais da rede de saúde 
não teriam sensibilidade necessária para atendê-la, pela orientação sexual. A usuária aceitou e a consulta foi marcada. (Diário de campo, 2019)

A citação acima evidencia uma postura comum em serviços de saúde, de colocar a mulher lésbica em um lugar de ausência de riscos em saúde sexual, pela sua prática com outras mulheres, reforçando o ideal preconcebido que atinge tanto os profissionais de saúde quanto as usuárias de não risco no sexo entre mulheres, colocando-as em situação de vulnerabilidade ao não oferecer informações, insumos de prevenção que possam ser adaptados à necessidade das lésbicas ou até mesmo um atendimento assistencial completo (com exame físico/ginecológico, solicitação de exames), como rotineiramente é realizado com mulheres que relatam estar em relações heterossexuais.

Ressaltamos que a noção de vulnerabilidade a que nos referimos foi trazida para área da saúde com maior destaque a partir da epidemia de Aids, inicialmente a temática da vulnerabilidade social foi trabalhada nos anos $90 \mathrm{com}$ foco na pobreza, tendo em vista conhecer as áreas da sociedade mais destituídas de provimento das necessidades básicas do que voltada à compreensão das determinantes desse processo de empobrecimento (MONTEIRO, 2011).

Alicerçada pela epidemia de Aids, essa discussão foi deslocada para o campo da saúde em uma perspectiva de superação da ideia de risco social, buscando ampliar a compreensão sobre o processo que leva aos agravos de saúde, deixando de lado o foco no individual e considerando os aspectos do contexto social do indivíduo como determinantes. Desta forma, a vulnerabilidade passa a ser compreendida, em seu complexo campo conceitual, por múltiplos condicionantes de diferentes naturezas (econômicos, culturais ou sociais), em que a vulnerabilidade não é inerente, mas determinada por condições e circunstâncias (MONTEIRO, 2011).

Pensando nisso, retomamos a reflexão sobre gênero e sua relação com o acesso a saúde. Além de ser utilizado como categoria de análise, o conceito de gênero trouxe outros avanços para o movimento feminista, dentre eles a problematização da categoria "mulher", antes vista a partir de um fundamentalismo biológico, agora contemplando uma complexa rede de características que exerceriam um papel dominante em certos contextos, mas não universais, trata-se de pensar nas mulheres em contextos específicos (PISCITELLI, 2002).

Porém, essa noção da categoria mulher ainda está distante da realidade do sistema de saúde, que continua a negar as diversas possibilidades do ser mulher, seguindo obstinado a classificar e enquadrar as mulheres no padrão social cisheteronormativo, codificando as condutas da área da saúde para um modelo hegemônico, negligenciando e atuando como determinante no processo de vulnerabilização de lésbicas no campo da saúde.

A partir do trecho do diário de campo é possível inferir um exemplo da percepção de grande parte das mulheres lésbicas sobre o risco da prática sexual com outra mulher, ao se ver em risco na relação com uma mulher bissexual, mas não demonstrar preocupação por si ao se relacionar com uma lésbica. Isto aponta uma das noções desse grupo sobre IST, de que seu maior risco está relacionado indiretamente ao sexo heterossexual (BARBOSA e FACCHINI, 2009).

Além disso, a pressuposição da heterossexualidade das mulheres que buscam cuidados em saúde configura outra razão para a situação de vulnerabilidade que as lésbicas se encontram, partindo da reflexão do discurso preventivo da saúde como campo em que se constitui o controle da (homo)sexualidade (CARVALHO, 2013). Cabe ainda refletir sobre o enfoque no risco de infecção às ISTs da maioria dos estudos sobre saúde lésbica, com uma importante ausência de discussão 
acerca dos processos sociais que atravessam a vivência lésbica e colocam essas mulheres em situação de risco, bem como o papel do feminismo na (não) produção de saúde para lésbicas.

Porém, cabe lembrar que ao compreendermos a vulnerabilidade social como resultado de um processo constituído por diferentes determinantes inseridas em um contexto histórico-social implica na possibilidade de minimizar ou reverter esse quadro, deslocando a noção de vulnerabilidade como algo que recai sobre as lésbicas, abrindo o debate para uma perspectiva com múltiplas possibilidades de mudança por meio da resistência aos processos sociais que conduziram essa população à atual situação de vulnerabilidade.

\section{Invisibilidade lésbica nas políticas públicas de saúde}

A situação de vulnerabilidade em saúde sexual e reprodutiva em que se encontram as mulheres lésbicas está exemplificada na não abertura no relacionamento para discutir aspectos relacionados à prevenção das IST/HIV, não percepção e desconsideração da vulnerabilidade às IST/HIV, não reconhecimento de si como sujeito de direitos sexuais e reprodutivos, entre outros aspectos (GUANILO, TAKAHASHI e BERTOLOZZI, 2014).

As lésbicas são comumente negligenciadas no que se refere aos cuidados em saúde, pois estão em situação de não-inteligibilidade pela sociedade e pelos profissionais de saúde, fator que resulta na ampliação da vulnerabilidade desse grupo que ao buscar o serviço de saúde não são orientadas ou inadequadamente orientadas, para o exercício da sua sexualidade de forma autônoma e segura (CARVALHO et al., 2013).

Apenas em 1984 ampliou-se o cuidado à mulher para além do período gestacional, com a criação do Programa de Assistência Integral em Saúde da Mulher (PAISM). Porém, a incorporação das relações de gênero e sexualidade só foram efetivamente inseridas nas políticas de saúde em 2004, por meio da Política Nacional de Atenção Integral à Saúde da Mulher (BRASIL, 2004; CARVALHO et al, 2013).

Assim, compreende-se que as lésbicas estão expostas ao risco de infecção por IST/HIV pela interligação de fatores individuais, sociais e programáticos. Ressalta-se que a invisibilidade desse grupo é em grande parte fruto do enfoque no discurso preventivo no risco à IST/HIV relacionado a práticas sexuais centradas no falo em contexto heterossexual e/ou homossexual masculino, negligenciando as diversas formas de expressão sexual, devido ao predomínio de representações cisheteronormativas na sociedade, fabricando a falsa percepção desse grupo como de baixo risco à infecção (MORA e MONTEIRO, 2013).

O trecho abaixo refere-se a um momento que ocorreu durante o curso de atualização do protocolo municipal de sífilis de Cuiabá, realizado em 2019. Neste momento do curso estava sendo discutido os aspectos jurídicos da abordagem ao usuário menor de idade em casos de IST.

\footnotetext{
Algumas enfermeiras começaram a relatar casos em que elas se viram em dúvida sobre como agir. Um desses casos foi explicitado por uma enfermeira que se levantou para falar, esta relatou que atendeu uma usuária menor de idade para realização de teste rápido, mas que ao descobrir que ela era lésbica não julgou necessário acionar a ginecologista para participar do caso e realizar exame ginecológico específico, pois como ela era lésbica não havia sexo com penetração e assim não haveria risco. (Diário de campo, 2019)
}

Em contraposição a essa falsa percepção, ainda que de acordo com a literatura atual o risco de transmissão sexual de IST/HIV seja maior na prática sexual 
penetrativa peniana, estudos recentes, indicam que o contato sexual entre lésbicas pode transmitir, entre outras IST, o Vírus do Papiloma Humano (HPV), tricomoníase, herpes genital e sífilis, além do HIV, que teve seu primeiro caso confirmado (por meio de contato sexual entre lésbicas) em março de 2014, pelo U.S Centers for Disease Control and Prevention (CDC) (TAT, MARRAZZO e GRAHAM, 2015; CHAN et al., 2014).

Corroborando essa afirmativa, em 2007 é lançado o Plano Integral de Enfrentamento da Feminização da Epidemia de Aids e outras IST, que visa promover a saúde sexual e reprodutiva, por meio de ações intersetoriais para garantir o acesso a insumos, diagnóstico e tratamento para IST/HIV/Aids em todo o país. O plano surge em face aos dados epidemiológicos alarmantes notificados até junho de 2006, sobre os casos novos de HIV, que demonstrava a feminização do HIV pela diminuição sistemática da razão de número de casos, passando de 15,1 homens por mulher, em 1986, para 1,5 homens por mulher, em 2005 (BRASIL, 2007).

Em 2017, o boletim epidemiológico demonstra que pouco mudou em relação aos dados de 2006, pois a razão de sexos para 2016, desconsiderando as gestantes, foi de 2,5 homens por mulher (BRASIL, 2017). Mora e Monteiro (2013) ressaltam a indicação de estudos anteriores de que a invisibilidade das lésbicas em relação às IST/HIV/Aids está diretamente ligada à inexistência de instrumentos de vigilância capazes de registrar suas práticas sexuais como via de transmissão às IST. Apontamento reforçado pelo próprio boletim epidemiológico, que traz dados estratificados por orientação sexual apenas para o gênero masculino, ao se tratar das mulheres o documento se refere apenas a gestantes, mulheres heterossexuais e usuárias de drogas injetáveis.

Entre as variáveis vinculadas à desigualdade de gênero que devem ser consideradas na busca do fortalecimento de ações para a saúde das lésbicas, destacase a negação dos direitos sexuais e reprodutivos das mulheres, por meio do revés em que se encontram os profissionais de saúde em relação a invisibilidade das questões de saúde sexual nesse universo, este é um dos fatores determinantes para a vulnerabilidade às IST/HIV para essa população. (BRASIL, 2007; SILVA, COSTA e MULLER, 2018; CARVALHO et al., 2013; BARBOSA e FACCHINI, 2009).

Para compreender este cenário de vulnerabilidade em saúde sexual que as mulheres lésbicas se encontram, é necessário retomar marcos históricos para as IST e sua relação com as sexualidades dissidentes. Para tanto, cito o início da epidemia de Aids na década de 1980, que permitiu o reforço da norma heterossexual no discurso preventivo e biomédico, não apenas no que se refere à Aids.

O controle sexual inserido nas políticas públicas de saúde é um marco do biopoder, conceito elaborado por Foucault, relacionado à prática de regulação dos sujeitos pelo estado por meio da subjugação dos corpos. Atrelado a esse movimento está a biopolítica, outro conceito de Foucault, que se refere a uma tecnologia de poder em que a população é tanto alvo quanto instrumento, estabelecendo uma relação entre corpos dóceis e domesticados com um senso de moralidade do corpo e da saúde (PELÚCIO e MISKOLCI, 2009).

De acordo com Pelúcio e Miskolci (2009), a ordenação, classificação e controle da sexualidade nesse contexto ocorreram a partir da forma como a saúde pública associou o HIV/Aids como sexualmente transmissível, admitindo e respaldando a crença no antagonismo entre desejo e ordem social, com o homoerotismo como ameaça à moral e saúde. 
A inclusão da pauta de saúde lésbica nas políticas de saúde enquanto sujeito em situação de vulnerabilidade às IST/HIV, apesar de trazer visibilidade às demandas do movimento lésbico, também possibilita a cooptação desse grupo pelo Estado por meio da biopolítica e que também normatiza os corpos dessas mulheres em uma perspectiva patológica dentro de um modelo de saúde ainda biomédico (CALDERARO, 2011).

Essa tensão entre direito e controle, como proposto por Foucault, revela o paradoxo de que o direito à saúde não ocorre sem o controle sobre os corpos. As relações de poder são ao mesmo tempo intencionais e não subjetivas, não há poder exercido sem um objetivo, porém não há poder sem resistência, estamos em uma constante correlação de forças permeadas pelos mecanismos de poder na esfera social (FOUCAULT, 1997).

Além disso, no momento da epidemia, é gerada uma intensa preocupação médica em se falar de sexo de forma exaustiva, de forma a ordenar os corpos e seus prazeres, bem como caracterizando a aids por uma sexualidade homossexual, no gênero masculino e com a raça/etnia da negritude e latinidade, deixando claro o teor homofóbico, racista e xenófobo, da saúde naquele momento. E ainda, a determinação desse grupo de risco revela a heteronormatividade das políticas públicas, que interpretavam a heterossexualidade como sexo sem risco para as mulheres, pressupondo a homossexualidade como sexo de risco (PELÚCIO e MISKOLCI, 2009).

Podemos utilizar as contribuições de Deleuze (1990) acerca do conceito de dispositivo, a partir da concepção foucaultiana, para pensar o dispositivo da saúde lésbica. Os dispositivos podem ser definidos como um conjunto assimétrico de forças distintas que ora se cruzam ora se dispersam, composto por três instâncias, poder-saber-subjetivação, que produzem o ver, falar e o fazer (CARVALHO, 2013).

Ao entender a saúde da mulher lésbica como dispositivo em que estão presentes as relações de saber-poder, é possível refletir sobre o processo de invisibilidade dessa pauta nas políticas públicas de saúde, ao passo que a não difusão dessa ideia tem um caráter produtivo que favorece outros dispositivos para a manutenção da matriz cisheteronormativa (CARVALHO, 2013).

O aparente crescimento de estudos sobre saúde sexual lésbica dão a entender que políticas públicas estão sendo pensadas e implementadas pelo Estado, porém, se nos aproximarmos com um olhar mais crítico destes estudos e políticas já produzidas, é possível observar a necessidade de aprofundamento nas especificidades dessa população e da ampliação da compreensão de saúde desse grupo, para que alcance sua forma integral e não esteja limitado à lógica biologicista, para além disso, é preciso pensar nos efeitos dos marcadores sociais da diferença na saúde dessas mulheres.

\section{Resistência ao apagamento social da mulher lésbica}

Em comparação à mulher heterossexual, que também é invisibilizada como sujeito vulnerável a IST, a mulher lésbica é apagada tanto das práticas sexuais quanto do contexto social. Adrienne Rich (2010) em clássico artigo feminista propõe a ideia de heterossexualidade compulsória como instituição política que retira o poder das mulheres, conforme veremos a seguir.

Existe uma suposição de que a maioria das mulheres são heterossexuais de modo inato, ideia que subsidia o apagamento da existência lésbica da história ou a sua ocorrência como algo excepcional, "acidental", negando a possibilidade do 
"ser" lésbica se tornar algo comum. Isso ocorre em parte porque ao reconhecer que a heterossexualidade pode não ser uma preferência das mulheres, mas algo imposto por estruturas que perpetuam a dominação masculina, é também reconhecer que existe outra alternativa para as mulheres, que elas não estão "naturalmente" predispostas à heterossexualidade e podem experienciar a vida como mulher lésbica (RICH, 2010).

Segundo Rich (2010) a existência lésbica é apagada por meio da demanda criada pela heterossexualidade compulsória, que denota a habilidade masculina em negar a sexualidade das mulheres ou forçá-las a isso. O capitalismo é exemplo de estrutura em que há segregação de gênero, por meio da qual as mulheres ocupam posição inferior na hierarquia do ambiente de trabalho (MACKINNON, 1979).

Mackinnon afirma que para além da segregação em serviços mal pagos, as mulheres são submetidas à sexualização no ambiente de trabalho. Para manter seu emprego, a mulher além de tolerar assédio sexual repetida vezes é ainda colocada em posição de reforçar a heterossexualidade cobrada socialmente, a lésbica não assumida é forçada a performar a feminilidade que se julga apropriada para uma mulher.

O processo que coloca a mulher lésbica nessa posição de vulnerabilidade está presente estruturalmente no contexto sócio-histórico permeado pelo machismo, racismo e lgbtfobia, sendo uma das determinantes nesse processo a violência. Para pensar sobre isso tomamos como referência a discussão acerca da violência simbólica, por Pierre Bourdieu, um conceito que pode ser utilizado para amparar discussões sobre a diferença da violência entre a homossexualidade masculina e feminina. Para Bourdieu (1999) a violência simbólica está associada à dominação simbólica a que as pessoas são submetidas, como nos domínios da raça, classe e gênero, se tratando do branco, burguês e masculino, respectivamente (VALADÃO e GOMES, 2011).

A perpetuação da violência seria uma das formas de silenciamento e apagamento da mulher lésbica, que por medo da violência não revela sua orientação sexual e/ou não desenvolve sua voz social. Tomamos como foco a violência simbólica, que pode ser entendida como aquela que é branda ou invisível, porém, ressaltamos que o uso do conceito de violência simbólica não busca minimizar ou esquecer o papel da violência física, nem com a intenção de colocá-las em oposição (BOURDIEU, 1999; BOURDIEU, 2003).

Observando a invisibilidade da lesbianidade, identificamos o estabelecimento da opressão como reflexo da negação da existência pública legitimada, sofrendo estigmatização que só é perceptível quando o movimento social reivindica seus direitos, buscando atingir a visibilidade (VALADÃO e GOMES, 2011).

Partindo das reflexões de Orlandi (2007), o silenciamento das mulheres é produção da opressão masculina, uma forma de violência simbólica, pois no discurso o sujeito e o sentido se constituem simultaneamente, ao silenciar as mulheres a sociedade proíbe que ela ocupe lugares e posições do sujeito, a sua identidade é afetada enquanto sujeito-do-discurso, pois a identidade resulta de processos de identificação em que o sujeito deve se inserir em um discurso.

Essa relação de dominação masculina e silenciamento são evidentes ao se tratar da sexualidade da mulher, que se agrava ainda mais ao considerar os eixos de articulação em que a mulher pode estar circunscrita, como raça e classe. A lésbica está inscrita em um processo de silenciamento ainda maior, pois a ela é negado não só o direito a fala, mas o não reconhecimento de sua existência. 
A heterossexualidade não é apenas uma orientação sexual, mas também uma ferramenta de controle, em sua forma compulsória busca manter a supremacia masculina como instrumento de poder, levando a mulher a construir toda a sua identidade em torno de homens. Esse "regime", mantem a hierarquia sexual, ao impor à mulher que se relacione com a ideia de homem para além do seu órgão genital, com a ideia socialmente construída de masculinidade.

Em posição de mais profunda desigualdade, estão as mulheres lésbicas negras, que passam por um duplo processo de apagamento, tanto pelo viés homofóbico quanto pelo racista. Tendo em vista viabilizar estudos que contemplem duas ou mais formas de subordinação, Kimberlé Crenshaw formula a noção de interseccionalidade, que permite a interação de eixos de subordinação que superam a ideia de simples sobreposição de opressões (PISCITELLI, 2008).

Ao mesmo tempo em que se percebem avanços, encontramos estudos que questionam o papel do feminismo ocidental na emancipação de mulheres, que de acordo com estes, impõe experiências e estruturas históricas para outras sociedades, na maioria das vezes desconsiderando o poder de organização de mulheres nas esferas religiosas, política, econômica e doméstica, invisibilizando a agência. Como desdobramento da dominação europeia e estabelecimento da hegemonia cultural euro-americana no mundo, o etnocentrismo e racialização do conhecimento são estabelecidos (GASPARETO e AMANCIO, 2017).

Desta forma, a simples sobreposição de padrões de dominação não é suficiente para o estudo de gênero, é necessário que uma interpretação aprofundada da esfera social e qualquer projeto emancipatório incorpore simultaneamente gênero, raça e classe, reforçando o questionamento em se tentar compreender as desigualdades presentes entre homens e mulheres apenas com uma dessas variáveis, de forma isolada (BIROLLI e MIGUEL, 2015).

A partir disso, nos propomos a provocar uma reflexão sobre a vulnerabilidade a que as mulheres lésbicas estão expostas, partindo da interseccionalidade, considerando as hierarquias que se constituem na convergência entre os eixos de gênero, raça e classe. Para entender a relação entre gênero, raça e classe, na perspectiva da interseccionalidade, é preciso entender as possibilidades das categorias de articulação, uma metáfora para indicar a existência de conexões entre diferentes tipos de coisas, estas estariam conectadas, mas não haveria uma identidade entre elas, mas sim uma unidade formada que as relaciona por suas diferenças e semelhanças. Desvendar o mecanismo que conecta as coisas, e a natureza da relação entre as partes seria o fundamental para compreender a subordinação das mulheres de acordo com seu contexto social (PISCITELLI, 2008).

Carla Akotirene (2020) ressalta que a interseccionalidade possibilita a análise das estruturas colonialistas que atravessam os corpos e são estabilizadas pela matriz de opressão, sob a forma de identidade. A interseccionalidade abala o reducionismo da política de identidade, indicando as estruturas coloniais que se articulam para promover a vulnerabilização da identidade.

As hierarquias de valor sexual atuam da mesma maneira que os sistemas ideológicos do racismo e etnocentrismo, racionalizando o bem-estar do sexualmente privilegiado, aquele "bom", "normal” e "natural", o heterossexual, monogâmico, reprodutivo e não-comercial, em contraposição ao "mal", "anormal", "não natural”, o homossexual, fora do casamento, promíscuo, não-reprodutivo (RUBIN, 1988).

Dentre as estratégias de regulação, Sedgwick (2007) reflete sobre o "armário" como um dispositivo de regulação da vida de gays e lésbicas, em sua obra ela pontua que mesmo em um nível individual, as pessoas abertamente homossexuais 
estão no armário com alguém que seja pessoal, econômica ou institucionalmente importante para elas, seja um novo grupo de estudantes, um novo chefe ou um novo médico.

Ao se pensar sobre o "armário" lésbico paralelamente ao "armário" gay, verificamos diferenças importantes que refletem a situação de desigualdade das mulheres mesmo quando comparada no mundo LGBTI+. Por exemplo, a mulher lésbica não assumida precisa reforçar sua feminilidade de acordo com os padrões socialmente aceitos para manter o emprego, resistir a violência física, verbal, sexual e simbólica, assim como todas as pessoas da comunidade LGBTI+, porém no que concerne ao atendimento em serviços de saúde a mulher lésbica não é sequer considerada como possibilidade.

É comum em serviços de saúde, principalmente nos especializados em IST/HIV/Aids, que a prática sexual homossexual masculina seja abertamente tratada durante $o$ atendimento. No entanto, práticas sexuais lésbicas são inteiramente desconhecidas e invisíveis, tanto para os profissionais de saúde quanto para a população em geral.

Corroborando essa afirmação estão as campanhas de prevenção às IST promovidas pelo Ministério da Saúde, constantemente com foco no uso de preservativo masculino ou peniano, com algum destaque para os casais homossexuais masculinos. Ademais, as estratégias de prevenção a nível nacional não contemplam as práticas sexuais de lésbicas, que por fim são forçadas a "adaptar" insumos de prevenção, como por exemplo, cortar o preservativo masculino ou feminino em forma retangular para criar uma barreira de proteção no sexo oral.

A existência lésbica, termo que sugere tanto a presença histórica de lésbicas quanto a criação contínua de significado para essa mesma existência, surge com um alcance mais abrangente para identificar essas mulheres. O continuum lésbico inclui uma gama de experiências de identificação da mulher, não apenas no contexto sexual, mas de forma a ampliar a compreensão sobre a história e psicologia feminina, rompendo a concepção de heterossexualidade inata e rejeitando esse modo compulsório de vida (PISCITELLI, 2008).

O continuum lésbico é uma categoria invisibilizada pela heterossexualidade compulsória, justamente pelo fato de subverter as relações impostas pelo patriarcado, tenta ocultar que outro caminho é possível, a partir da potencialidade das relações de união entre as mulheres.

Pensar os direitos sexuais e reprodutivos das mulheres é levar em consideração a vivência plena da sexualidade e compreender a saúde da mulher lésbica como um dispositivo que perpassa correlações de forças da hierarquia saber-poder, que moldam e guiam as políticas públicas, assim como toda a sociedade.

\section{Considerações finais}

Este trabalho se propôs a explorar a vulnerabilidade em saúde de mulheres lésbicas por compreender sua situação de não inteligibilidade social que resulta na invisibilidade de suas demandas junto aos serviços de saúde e à sociedade como um todo.

Para tanto, percorremos teorias de gênero e sexualidade que deram subsídio teórico às proposições realizadas aqui. Além disso, foi pontuada a necessidade em se trabalhar as categorias de articulação para pôr em prática a perspectiva da interseccionalidade, considerando os eixos de gênero, raça e classe social. Eviden- 
temente, a garantia de direitos sexuais e reprodutivos das mulheres é tema essencial a ser debatido, tendo em vista a vulnerabilidade dessa população, que se aprofunda ainda mais ao considerar os eixos supracitados.

Neste contexto, retomar a discussão sobre visibilidade e existência lésbica, surge como papel da área acadêmica, mas também dos movimentos sociais LGBTI+, das mulheres, do feminismo em si, para que a luta por garantia de direitos não se limite às mulheres não negras, heterossexuais de classe média, mas sim contemplando a gama de diversidade que as mulheres apresentam, levando em consideração seu contexto histórico-social e sua agência enquanto sujeito de direitos.

O corpo da mulher tem sido qualificado (ao se tratar do ideal romântico, reprodutivo, monogâmico e biológico) e desqualificado (quando se trata de sua livre expressão sexual, a partir de uma concepção libertadora de não obrigatoriedade inata da heterossexualidade) em um processo histórico de manutenção da hierarquia sexual e supremacia masculina. Para além de refletir sobre as relações que garantem a perpetuação da subordinação da mulher, é fundamental questionar para quem estes estudos são feitos, em quais espaços ele é discutido e que mudanças sociais eles produzem.

Recebido em 19 de setembro de 2019.

Aprovado em 8 de agosto de 2020.

\section{Referências}

AKOTIRENE, C. Interseccionalidade. São Paulo: Sueli Carneiro/Jandaíra, 2020.

BARBOSA, R.M.; FACCHINI, R. Acesso a cuidados relativos à saúde sexual entre mulheres que fazem sexo com mulheres em São Paulo, Brasil. Cadernos de Saúde Pública, 25 (sup. 2): 291-300, 2009.

BIROLI, F.; MIGUEL, L.F. Gênero, raça, classe. Opressões cruzadas e convergências na reprodução das desigualdades. Mediações, 20 (2): 27-55, 2015.

BOURDIEU, P. A dominação masculina. Tradução Maria Helena Kühner. Rio de Janeiro: Bertrand Brasil, 1999.

BOURDIEU, Pierre. O poder simbólico. 6 ed. Tradução Fernando Tomaz. Rio de Janeiro: Bertrand Brasil, 2003.

BRASIL. Lei $n$. 8o80, de 19 de setembro de 199o. Dispõe sobre as condições para a promoção, proteção e recuperação da saúde, a organização e o funcionamento dos serviços correspondentes e dá outras providências. Brasília, 1990.

BRASIL. Ministério da Saúde. Carta dos direitos dos usuários da saúde. Brasília, 2012. 
BRASIL. Ministério da Saúde. Secretaria de Atenção à Saúde. Departamento de Ações Programáticas Estratégicas. Política Nacional de Atenção Integral à Saúde da Mulher. Brasília, 2004.

BRASIL. Ministério da Saúde. Secretaria de Vigilância em Saúde. Boletim Epidemiológico: HIV/AIDS. Brasília, 2017.

BRASIL. Ministério da Saúde. Secretaria de Vigilância em Saúde. Programa Nacional de DST e Aids. Plano Integrado de Enfrentamento da Feminização da Epidemia de Aids e outras DST. Brasília, 2007.

BRASIL. Secretaria de Políticas para as Mulheres. Relatório da Oficina “Atenção Integral à Saúde de Mulheres Lésbicas e Bissexuais”. Brasília, 2014.

BUTLER, J. Problemas de gênero. Rio de Janeiro: Civilização Brasileira, 2003. pp. 17-6o.

CARVALHO, P.M.G. et al. Prevenção de doenças sexualmente transmissíveis por mulheres homossexuais e bissexuais: estudo descritivo. Online Braz J Nurs., 12 (4): 931-41, 2013.

CARVALHO, S. S.; CALDERARO, F.; SOUZA, S. J. O dispositivo "Saúde de mulheres lésbicas”. (In)visibilidade e direitos. Psicologia Política, 13 (26): 111-127, 2013 .

CHAN, S. K.; THORNTON, L. R.; CHRONISTER, K. J et al. Likely female to female sexual transmission of HIV-Texas, 2012. MMWR Morb Mortal., 63 (10): 209-212, 2014.

FERREIRA, B.O. et al. Vivências de travestis no acesso ao SUS. Physis: Revista de Saúde Coletiva, 27 (4): 1023-1038, 2017.

FOUCAULT, M. História da sexualidade I. Rio de Janeiro: Graal, 1997.

GASPARETTO, V. F.; AMANCIO, H. P. "Gênero e feminismos em África. Temas, problemas e perspectivas 4 analíticas". Seminário Internacional Fazendo Gênero 11 \& 13th Women's Worlds Congress (Anais Eletrônicos), 2017.

GOMES, R. et al. Gênero, direitos sexuais e suas implicações na saúde. Ciência \& Saúde Coletiva. Rio de Janeiro, 26 (6): 1997-2005, 2018.

GUANILO, M.C.D.T.U.; TAKAHASHI, R.F.; BERTOLOZZI, M.R. “Avaliação da vulnerabilidade de mulheres às Doenças Sexualmente Transmissíveis - DST e ao HIV: construção e validação de marcadores”. Rev. Esc. Enferm. USP., 48 (Esp.): 156-63, 2014.

LIONÇO, T. Que direito à saúde para a população GLBT? Considerando direitos humanos, sexuais e reprodutivos em busca da integralidade e da equidade. Saúde e Sociedade, 17 (2): 11-21, 2008.

MACKINNON, C.A. Sexual Harassment of Working Woman: a case of sex discrimination. Yale: Yale University Press, 1979.

MONTEIRO, S. R. R. P. O marco conceitual da vulnerabilidade social. Sociedade em Debate, 17 (2): 29-40, 2011.

MORA, C. M.; MONTEIRO, S. Homoerotismo feminino, juventude e vulnerabilidade às DSTs/Aids. Estudos Feministas, 21 (3): 905-26, 2013.

ORLANDI, E. P. As formas do silêncio: no movimento dos sentidos. $6^{\mathrm{a}}$ ed. Campinas: Editora da Unicamp, 2007. 
ORTNER, Sherry. "Está a mulher para a natureza, assim como o homem para a cultura?” In: ROSALDO, Michelle Z.; LAMPHERE, L. (org.). A mulher, a cultura, a sociedade. Rio de Janeiro: Paz e Terra, 1979.

PELÚCIO, L.; MISKOLCI, R. A prevenção do desvio: o dispositivo da aids e a repatologização das sexualidades dissidentes. Sexualidad, Salud y Sociedad, 1 (1): 125-157, 2009.

PISCITELLI, A. "Gênero: a história de um conceito". In: BUARQUE DE ALMEIDA, H.; SZWAKO, J. (org.). Diferenças, igualdade. São Paulo: Berlendis \& Vertecchia, 2009. pp. 116-148.

PISCITELLI, A. Interseccionalidades, categorias de articulação e experiências de migrantes brasileiras. Sociedade e Cultura, 11 (2): 263-274, 2008.

PISCITELLI, A. "Re-criando a categoria mulher?" In: ALGRANTI, L. (org.). $A$ prática feminista e o conceito de gênero. Textos didáticos, vol. 48. Campinas: IFCH/Unicamp, 2002. pp. 7-42.

RICH, A. Heterossexualidade compulsória e existência lésbica. Bagoas, 5 (1): 1744, 2010.

RUBIN, G. "Thinking Sex: notes for a radical theory of the politics of sexuality." In: NARDI, P.; SCHNEIDER, B. (eds.) Social perspectives in lesbian and gay studies. London: Routledge, 1998.

SAMPAIO, J. et al. Ele não Quer com Camisinha e eu Quero me Prevenir: exposição de adolescentes do sexo feminino às DST/aids no semiárido nordestino. Saúde e Sociedade, 20 (1): 171-181, 2011.

SCOTT, J. Gênero: uma categoria útil de análise histórica. Educação \& Realidade, 20 (2): 71-99, 1995.

SEDGWICK, E. K. A epistemologia do armário. Cadernos Pagu, 28 (1): 19- 54, 2007.

SILVA, D. R. Q.; COSTA, Z. L. S.; MULLER, M. B. C. Gênero, sexualidade e políticas públicas. Educação \& Realidade, 41 (1): 49-58, 2018.

TAT, S. A.; MARRAZZO, J. M.; GRAHAM, S. M. Women Who Have Sex with Women Living in Low- and Middle-Income Countries: A Systematic Review of Sexual Health and Risk Behaviors. LGBT Health, 2 (2), 2015. 
VOLUME 8

NÚMERO 16

(JAN , / ABR , 2021)

PRAZO FINAL DE SUBMISSÃO:

30 DE JANEIRO DE 2021

\section{A}
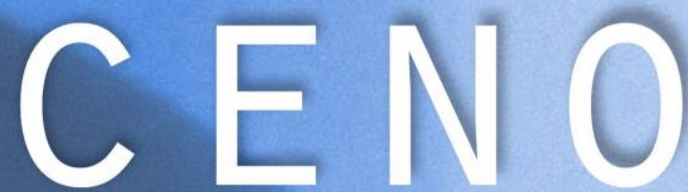

REEIISTTA DE ANITROPOLOGIA DO CENTRO-OESTE

ISSN: $2358-5587$

CHAMADA DE ARTIGOS DOSSIE TEMÁTICO:

\section{EPISTEMOLOGIAS, METODOLOGIAS E QUESTÕES ÉTICAS EM PESQUISAS COM ABORDAGENS EM DIVERSIDADES SEXUAIS E DE GÊNERO}

(v. 8, N. 16, 2021)

COORDENADORXS:

ESTEVÃO FERNANDES (UNIR, PPGAS/UFMT)

MARIANE PISANI (UFT)

MOISÉS LOPES (PPGAS/UFMT)

Simone de OLiveira Mestre (UNIFAL-MG, PPGS/UFMg)

ste dossiê busca congregar pesquisas e reflexões em torno das

1 diversidades sexuais e de gênero, com especial foco nos debates a respeito de outras possibilidades de desenvolvimento de

investigações que problematizem o ponto de vista teórico-metodológico e ético constituído a partir da história colonial do Ocidente. Neste sentido, buscamos contribuições que dialoguem com os estudos feministas, LGBTs, com as leituras pós-coloniais, teoria queer e/ou tomem como ponto de discussão as epistemologias, metodologias e questões éticas que envolvam pesquisas com abordagem em diversidades sexuais e de gênero.

Muito já se tem escrito sobre a necessidade de descolonizar essas abordagens, seja a partir de uma "epistemologia cucaracha" de uma "teoria cú" (PELÚCIO, 2014); do "queer decolonial” (PEREIRA, 2015); do "queer caboclo" (FERNANDES e GONTIJO, 2016) ou mesmo das discussões que envolvem o feminismo decolonial (GONZALEZ, 1988; LUGONES, 2008; SEGATO, 2013): todas essas reflexões se tornaram relevantes e fundamentais para compreensão das questões que envolvem as diversidades sexuais e de gênero no chamado Sul Global. Desse modo, neste dossiê, buscamos provocar diálogos que rompam com uma visão heterocentrada, falogocêntrica, metropolitana, normativa e colonizadora das diversidades sexuais e de gênero com o intuito de tensionar as produções desenvolvidas a partir das realidades brasileiras e latino-americanas, buscando uma

ampliação crítica e perturbadora do status quo dessas investigações. Assim, a partir desses pressupostos e debates/embates, acolheremos contribuições que possibilitem tanto a exploração de temas e problemas já consolidados pelo campo de estudos sobre diversidades sexuais e de gênero quanto - e principalmente - sua ampliação. 